\title{
Critical Conditions for the Ignition of a Gel Fuel under Different Heating Schemes
}

\author{
Olga Gaidukova and Pavel Strizhak*(D) \\ Heat and Mass Transfer Simulation Laboratory, National Research Tomsk Polytechnic University, 634050 Tomsk, \\ Russia; osy1@tpu.ru \\ * Correspondence: pavelspa@tpu.ru
}

check for updates

Citation: Gaidukova, O.; Strizhak, P. Critical Conditions for the Ignition of a Gel Fuel under Different Heating Schemes. Energies 2021, 14, 7083. https://doi.org/10.3390/en14217083

Academic Editor: Francesco Frusteri

Received: 3 September 2021

Accepted: 21 October 2021

Published: 29 October 2021

Publisher's Note: MDPI stays neutral with regard to jurisdictional claims in published maps and institutional affiliations.

Copyright: (c) 2021 by the authors. Licensee MDPI, Basel, Switzerland. This article is an open access article distributed under the terms and conditions of the Creative Commons Attribution (CC BY) license (https:/ / creativecommons.org/licenses/by/ $4.0 /)$.

\begin{abstract}
A model was developed to research the critical conditions and time characteristics of the ignition of gel fuels in the course of conductive, convective, radiant and mixed heat transfer. MATLAB was used for numerical modeling. Original MATLAB code was established pursuant to the developed mathematical model. For gel fuel ignition at initial temperatures corresponding to cryogenic storage conditions with different heating schemes, a numerical analysis of interconnected processes of heat and mass transfer in the chemical reaction conditions and exothermic and endothermic phase transitions was conducted. The model was tested by comparing the theoretical results with the experimental data. Dependencies were established between the key process characteristic (i.e., the ignition delay time) and the ambient temperature when the following parameters were varied: emissivity, heat emission coefficient, activation energy and pre-exponential factor of the fuel vapor oxidation reaction. The critical values of the main parameters of the energy source were determined. For these values, gel fuel ignition conditions were consistently realized for each heating scheme. The critical heat fluxes necessary and sufficient for the ignition of typical gel fuels were determined.
\end{abstract}

Keywords: gel fuel; conductive heating; radiant heat flux; convective heat flux; ignition; critical conditions

\section{Introduction}

Currently, there is a trend toward a significant decrease in energy resource reserves in many regions of the world, accompanied by increased demand for available and clean energy [1]. Therefore, the use of alternative sources for expanding the resource base and ensuring energy safety is a promising trend [2]. Gel fuel is a type of condensed substance that combines the advantages of solid and liquid fuels [2-4]. Research on gel fuels is customarily subdivided into four areas: rheology $[5,6]$, preparation $[7,8]$, transportation and atomization [9] and combustion in rockets and power plants [10,11]. The widespread use of gel fuels in the power industry requires a detailed investigation of the characteristics and patterns of their ignition and combustion processes. The results obtained in this research are required for the correct design and engineering of power generation facilities (combustion chambers of boilers, engines, etc.) [12].

References [13-18] present experimental studies in which gel fuel droplet combustion characteristics were investigated to specify the mechanisms for multicomponent fuels. The critical conditions of the combustion of gel fuels significantly differ from the processes that characterize the combustion of conventional liquid and solid fuels $[7,14,19]$. The development of mathematical models is an important task allowing a full-scale investigation of such processes. This is impossible to achieve in experimental conditions due to fire and explosion safety considerations and the need to provide special conditions for conducting the experiments [7]. Gel fuel droplets are characterized by complex fluctuations in size, both during evaporation and combustion, in contrast to the quasi-stationary combustion of conventional liquid fuel droplets [20]. The developed model is presented in [20]. This is a model of nonstationary combustion of a droplet of a gel fuel based on unsymmetrical 
dimethylhydrazine. The results of the numerical simulation [20] substantiated the fluctuations of both the radius of the droplet and the mass fraction of dimethylhydrazine vapor on the droplet surface after the formation of a gel film. The gel fuel droplet combustion process included four stages [20]: the formation of a gel-former film, high-frequency rupture of the gel-former film, low-frequency rupture of the gel-former film and the decomposition of the gel former. The model presented in [21] simulates a diffusion flame arising during the atomization of a gel fuel based on an organic thickener. Atomized gel fuel is characterized by vibrational evaporation when the medium surrounding the gel droplet reaches a certain critical temperature. The simulation results [21] showed that the evaporation of combusting gel droplets has a significant effect on the flame characteristics and the thermal field in the diffusion flame front. Areas of high temperatures and heat dissipation (usually referred to as hot spots) were formed from individual or multiple combusting droplets. Under certain operating conditions, this can result in higher temperatures than those in the main homogeneous flame environment. This can be extremely important in a production environment when hot spots in unwanted areas of combustion zones can compromise the structural integrity of the chamber. Thus, while gel fuels have advantages over liquid fuels, it is imperative to maintain stringent operating conditions when burning gel fuels to achieve the desired combustion characteristics. Reference [22] presents a mathematical model of the combustion of gel fuel droplets. The results showed that the rate of evaporation of liquid fuel from the droplet surface depends on the droplet size and significantly affects the thickness of the gel-forming layer. The tensile stress applied to the gel-forming layer during bubble formation reaches high values in short periods and causes the droplet to break when the tensile stress exceeds the breaking stress of the layer material. The gel-forming layer formation stage is three times longer than the bubble formation and layer rupture stage [22]. In [23], a mathematical model of hydrazine-based gel fuel ignition under conductive heating by a hot metal particle of a cylindrical shape is presented. It was found that gel fuel ignition delay times during conductive heating vary in the range of $0.02-0.8 \mathrm{~s}$. To ignite a droplet of gel fuel, a critical heat flux density of $60-950 \mathrm{~kW} / \mathrm{m}^{2}$ is required. This density varies depending on the dimensions (radius range: $2.5-10 \mathrm{~mm}$, height range: 5-20 mm) and the initial temperature of the metal cylinder (840-1500 K) [23]. In [24], a model of ignition of a typical particle of a gel fuel based on an organic polymer thickener in a high-temperature air environment is presented. The fuel ignition delay times are varied between $0.3 \mathrm{~s}$ and $10 \mathrm{~s}$ at the air temperature of $800-1473 \mathrm{~K}$ and a particle radius of $0.5-2.0 \mathrm{~mm}$.

To date, results of theoretical studies of consistent patterns in the ignition processes of gel fuels have been obtained, and they are limited in terms of their field of application. There are no data on modeling the ignition and combustion of gel fuels under different heating schemes where the dominance of radiant, conductive and convective heat fluxes would be taken into account. Thus, the purpose of this study is to determine the critical conditions of initiation of stable combustion of typical gel fuels while taking into account a group of related processes of heat and mass transfer, chemical reactions and phase transitions under conductive, convective and radiant heating and at very low initial fuel temperature (typical for cryogenic storage conditions).

\section{Physical and Mathematical Models}

\subsection{Dominance of Conductive Heat Flux on the Surface of a Gel Fuel Sample}

When formulating the problem statement, it was assumed that a sample of gel fuel is located on the side of a metal cylinder heated to high temperatures (Figure 1). The cylinder temperature was $203 \mathrm{~K}$ (a typical cryogenic storage temperature for gel fuels [25]). When a fuel is used at low temperatures, its initial temperature is one of the main factors affecting the inertia of the combustion process [26,27]. The fuel contains a thickener and a flammable liquid. The volume fractions of fuel $(\varphi)$ and oxidizer $(1-\varphi)$ in the condensed matter are known. The energy of the cylinder provides for the heating of the near-surface layer of the fuel (radiant, convective and conductive mechanisms of heat transfer were taken into 
account). If fuel temperature at the initial moment of time is negative, then the processes of fuel melting are accelerated. When the vaporization conditions are achieved, the thickener evaporates. Fuel vapors enter the area filled with the inert gas. In the near vicinity of the particle, a vapor-gas mixture is formed. The mixture contains the fuel and the inert gas.

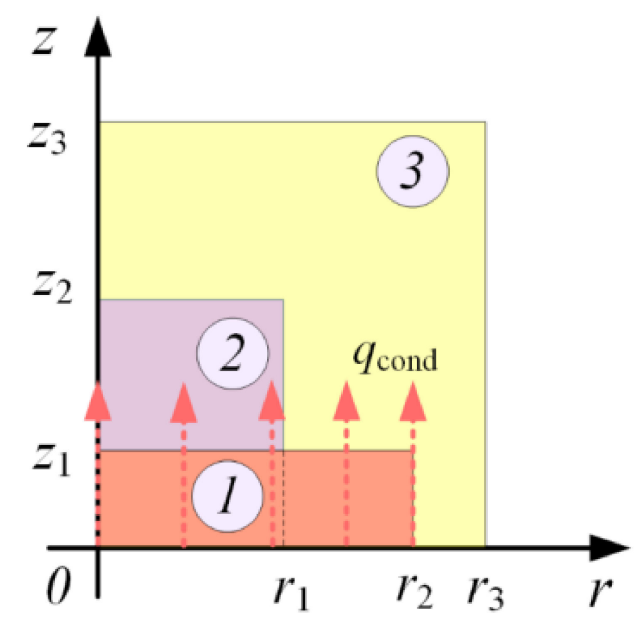

Figure 1. Scheme of the solution domain for the heat and mass transfer problem under conductive heating: 1-heating surface; 2-gel fuel sample; 3-air.

When the temperatures and concentrations of the mixture components sufficient for ignition are reached, ignition occurs [28]. The time interval between the moment when the fuel sample hits the cylinder surface and until the ignition conditions are met is the ignition delay time $\tau$. In the simulation, a small metal cylinder $\left(R_{p}\right.$ and $\left.Z_{p}\right)$ was assumed to be the heating source. The ignition criteria used in the formulation of the problem of heat and mass transfer (Figure 1) were assumed according to the concepts of the modern theory of ignition of condensed substances [29]: (i) the energy released as a result of the chemical reaction of oxidation of the fuel is greater than the heat transferred from the heated particle to the fuel and the formed vapor-gas mixture; (ii) the temperature of the mixture of gaseous fuel components in the oxidation reaction zone exceeds the initial temperature of the heating source [29]. The solution domain for the heat and mass transfer problem during conductive heating is shown in Figure 1.

The parameters corresponding to References [23,29] carried out with typical and most promising gel fuels were used as the initial data in the numerical simulation (Table 1).

Time-averaged thermophysical characteristics of a gel fuel sample ( $50 \mathrm{vol} \%$ oil; $48 \mathrm{vol} \%$ aqueous solution of PVA (10 wt.\%); 2 vol.\% emulsifier) are presented in Table 1 [23]. In the simulation, the symmetric configuration of the fuel sample was considered.

In the course of the research, the temperature of the external environment with respect to the fuel sample was adjusted in the range of $873-1273 \mathrm{~K}$, covering the minimum temperatures required to initiate the combustion of the gel fuels being investigated [30]. The higher the temperature of the heating source, the quicker the temperature in the near-surface fuel layer is stabilized. The intensification of the thickener evaporation process at sufficiently high heating temperatures leads to an increase in the heat consumption supporting this process. Therefore, increasing the temperature above $1273 \mathrm{~K}$ is impractical [29]. In real-life fuel applications, the energy supply scheme for initiating the combustion can be different. It may involve the dominance of convective, conductive or radiant heat transfer, as well as mixed heat transfer [29]. Thus, varying the main parameters of heat transfer (the emissivity and the air flow rate) for each scheme has a major role in the research of the fuel combustion process. It is also important for the substantiation of the design characteristics and layouts of modern furnaces and combustion chambers for the purpose of increasing the combustion efficiency. Emissivity variations in the range of $0.85-0.99$ correspond to the respective ranges for typical muffle furnace wall materials and various modern combustion 
chambers [31]. The heat transfer coefficient was varied in the range of $0-200 \mathrm{~W} /\left(\mathrm{m}^{2} \cdot \mathrm{K}\right)$, which corresponds to an air flow rate between 0 and $6 \mathrm{~m} / \mathrm{s}$, i.e., it covers the conditions where natural and forced convection are dominant. The variation of the activation energy and the pre-exponential factor makes it possible to isolate the effect of these parameters on the chemical reaction processes of fuel ignition. Thus, with the variation of these parameter values, it is possible to establish the critical conditions for the initiation of the combustion of fuels with different component compositions.

Table 1. Data for the numerical simulation $[23,29]$.

\begin{tabular}{|c|c|c|c|}
\hline Constant & Symbol & Value & Unit of Measurement \\
\hline Diffusion coefficient & $D$ & $7.83 \times 10^{-5}$ & $\mathrm{~m}^{2} / \mathrm{s}$ \\
\hline Oxidizing reaction activation energy & $E_{\mathrm{a}}$ & $60 \times 10^{3}$ & $\mathrm{~J} / \mathrm{mol}$ \\
\hline Oxidizing reaction pre-exponential factor & $k_{0}$ & $8 \times 10^{1}$ & $\mathrm{~s}^{-1}$ \\
\hline Specific heat of gel fuel & $C_{f}$ & 1380 & $\mathrm{~J} /(\mathrm{kg} \cdot \mathrm{K})$ \\
\hline Temperature of gel fuel & $T_{f}$ & 203 & $\mathrm{~K}$ \\
\hline Temperature of surface under radiation heating & $T_{h}$ & $873-1273$ & $\mathrm{~K}$ \\
\hline Temperature of air & $T_{a}$ & $873-1273$ & K \\
\hline Thermal effect of oxidant evaporation & $Q_{\mathrm{eo}}$ & $38 \times 10^{6}$ & $\mathrm{~J} / \mathrm{kg}$ \\
\hline Thermal effect of fuel vaporization & $\widetilde{Q}_{\mathrm{ef}}$ & $0.14 \times 10^{6}$ & $\mathrm{~J} / \mathrm{kg}$ \\
\hline Thermal effect of vaporization of the thickener & $Q_{\text {ispz }}$ & $0.26 \times 10^{6}$ & $\mathrm{~J} / \mathrm{kg}$ \\
\hline Fuel evaporation mass rate & $W_{\text {ef }}$ & $25 \times 10^{-3}$ & $\mathrm{~kg} /\left(\mathrm{m}^{2} \cdot \mathrm{s}\right)$ \\
\hline Oxidant evaporation mass rate & $W_{e o}$ & $15.3 \times 10^{-3}$ & $\mathrm{~kg} /\left(\mathrm{m}^{2} \cdot \mathrm{s}\right)$ \\
\hline Diffusion rate & $U_{\mathrm{v}}$ & $0-6$ & $\mathrm{~m} / \mathrm{s}$ \\
\hline Convection heat transfer coefficient & $\alpha$ & $0-200$ & $\mathrm{~W} /\left(\mathrm{m}^{2} \cdot \mathrm{K}\right)$ \\
\hline Coefficient of thermal expansion & $\beta$ & 0.001 & $\mathrm{~K}^{-1}$ \\
\hline Gravity acceleration & $g$ & 9.8 & $\mathrm{~m} / \mathrm{s}^{2}$ \\
\hline Emissivity & $\stackrel{\circ}{\varepsilon}$ & $0.85-0.99$ & - \\
\hline Kinetic viscosity & $v$ & $14.1 \times 10^{-6}$ & $\mathrm{~m}^{2} / \mathrm{s}$ \\
\hline Density of gel fuel & $\rho_{f}$ & 1010 & $\mathrm{~kg} / \mathrm{m}^{3}$ \\
\hline Thermal conductivity of gel fuel & $\lambda_{f}$ & 0.16 & $\mathrm{~W} /(\mathrm{m} \cdot \mathrm{K})$ \\
\hline Dimensionless combustible part of fuel & $\varphi$ & 0.5 & - \\
\hline
\end{tabular}

As a result of theoretical research, the values of ignition delay times for promising gel fuels were calculated. These parameters are among the main ones that characterize the ignition process [18]. The previously determined ignition delay time values make it possible to choose optimal combustion chamber designs and chamber dimensions.

To explain a complex of related heat and mass transfer processes under chemical reaction conditions as well as endothermic and exothermic phase transitions at $0<\tau<\tau_{d}$, a system of nonstationary partial differential equations was used [29,32]:

For the steam-gas mixture $\left(0<r<r_{1}, z_{2}<z<z_{\mathrm{L}}, r_{1}<r<r_{\mathrm{L}}, z_{1}<z<z_{\mathrm{L}}, r_{2}<r<r_{\mathrm{L}}\right.$, $\left.0<z<z_{1}\right)$ :

Continuity equation:

$$
\frac{\partial^{2} \psi}{\partial z^{2}}+\frac{1}{r} \frac{\partial \psi}{\partial r}+\frac{\partial^{2} \psi}{\partial r^{2}}=\omega
$$

Motion equation of the steam-gas mixture:

$$
\frac{\partial \omega}{\partial \tau}+u \frac{\partial \omega}{\partial r}+w \frac{\partial \omega}{\partial z}=v_{a}\left[\frac{\partial^{2} \omega}{\partial r^{2}}+\frac{1}{r} \frac{\partial \omega}{\partial r}+\frac{\partial^{2} \omega}{\partial z^{2}}\right]+\beta g \frac{\partial T_{a}}{\partial z} ;
$$

Equation of energy for the vapor-gas mixture:

$$
\frac{\partial T_{a}}{\partial \tau}+u \frac{\partial T_{a}}{\partial r}+w \frac{\partial T_{a}}{\partial z}=a_{a}\left[\frac{\partial^{2} T_{a}}{\partial r^{2}}+\frac{1}{r} \frac{\partial T_{a}}{\partial r}+\frac{\partial^{2} T_{a}}{\partial z^{2}}\right] ;
$$


Fuel vapors' diffusion equation:

$$
\frac{\partial C_{f}}{\partial \tau}+u \frac{\partial C_{f}}{\partial r}+w \frac{\partial C_{f}}{\partial z}=D_{12}\left[\frac{\partial^{2} C_{f}}{\partial r^{2}}+\frac{1}{r} \frac{\partial C_{f}}{\partial r}+\frac{\partial^{2} C_{f}}{\partial z^{2}}\right] ;
$$

Oxidizer vapors' diffusion equation:

$$
\frac{\partial C_{\mathrm{o}}}{\partial \tau}+u \frac{\partial C_{\mathrm{o}}}{\partial r}+w \frac{\partial C_{\mathrm{o}}}{\partial z}=D_{13}\left[\frac{\partial^{2} C_{\mathrm{o}}}{\partial r^{2}}+\frac{1}{r} \frac{\partial C_{\mathrm{o}}}{\partial r}+\frac{\partial^{2} C_{\mathrm{o}}}{\partial z^{2}}\right] ;
$$

Equation of balance for the vapor-gas mixture:

$$
C_{\mathrm{f}}+C_{\mathrm{g}}+C_{0}=1 ;
$$

Equation of thermal conductivity for the fuel $\left(0<r<r_{1}, z_{1}<z<z_{2}\right)$ :

$$
\frac{\partial T_{h}}{\partial \tau}=a_{h}\left[\frac{\partial^{2} T_{h}}{\partial r^{2}}+\frac{1}{r} \frac{\partial T h}{\partial r}+\frac{\partial^{2} T_{h}}{\partial z^{2}}\right]-\frac{W_{\text {melt }} Q_{\text {melt }}}{z_{L} \rho_{h} C_{h}} .
$$

Initial conditions: $T=T_{\mathrm{h}}$ at $0<r<r_{2}, 0<z<z_{1} ; T=T_{f}$ at $0<r<r_{1}, z_{1}<z<z_{2} ; T=T_{\mathrm{a}}$, $C_{f}=0, \psi=0, \omega=0$ at $0<r<r_{1}, z_{2}<z<z_{\mathrm{L}}, r_{1}<r<r_{\mathrm{L}}, z_{1}<z<z_{\mathrm{L}}, r_{2}<r<r_{\mathrm{L}}, 0<z<z_{1}$.

Boundary conditions:

$$
\begin{gathered}
r=0,0<z<z_{1} \frac{\partial T_{h}}{\partial r}=0 ; r=r_{2}, 0<z<z_{1}-\lambda_{h} \frac{\partial T_{h}}{\partial r}=-\lambda_{a} \frac{\partial T_{a}}{\partial r} ; \frac{\partial C_{f}}{\partial r}=0 ; \\
r=r_{\mathrm{L}}, 0<z<z_{1} \frac{\partial^{2} T_{a}}{\partial r^{2}}=0 ; \frac{\partial^{2} C_{f}}{\partial r^{2}}=0 ; \frac{\partial \psi}{\partial r}=0 ; \\
r=0, z_{1}<z<z_{2}, \frac{\partial T_{f}}{\partial r}=0 ; \\
r=r_{1}, z_{1}<z<z_{2},-\lambda_{a} \frac{\partial T_{a}}{\partial r}-Q_{\mathrm{ef}} W_{\mathrm{ef}}-Q_{\mathrm{eo}} W_{\mathrm{eo}}=-\lambda_{f} \frac{\partial T_{f}}{\partial r} ; \rho_{12} D \frac{\partial C_{f}}{\partial r}=W_{e f} ; \\
\frac{\partial \psi}{\partial r}=\frac{W_{e f}}{\rho_{12}} ; r=r_{\mathrm{L}}, z_{1}<z<z_{2} \frac{\partial^{2} T_{a}}{\partial r^{2}}=0 ; \frac{\partial^{2} C_{f}}{\partial r^{2}}=0 ; \frac{\partial \psi}{\partial r}=0 ; \\
r=0, z_{2}<z<z_{\mathrm{L}}, \frac{\partial T_{a}}{\partial r}=0 ; \frac{\partial C_{f}}{\partial r}=0 ; \frac{\partial \psi}{\partial r}=0 ; r=r_{\mathrm{L}}, z_{2}<z<z_{\mathrm{L}} \frac{\partial^{2} T_{a}}{\partial r^{2}}=0 ; \\
z=0,0<r<r_{2}, \frac{\partial T_{h}}{\partial z}=0 ; z=0, r_{2}<r<r_{\mathrm{L}}, \frac{\partial T_{a}}{\partial z}=0 ; \frac{\partial C_{f}}{\partial z}=0 ; \frac{\partial \psi}{\partial z}=0 ; \\
z=z_{1}, 0<r<r_{1}-\lambda_{h} \frac{\partial T_{h}}{\partial z}-Q_{\mathrm{ef}} W_{\mathrm{ef}}-Q_{\mathrm{eo}} W_{\mathrm{eo}}=-\lambda_{f} \frac{\partial T_{f}}{\partial z} ; \rho_{12} D \frac{\partial C_{f}}{\partial z}=W_{e f} ; \\
z=z_{1}, r_{1}<r<r_{2},-\lambda_{h} \frac{\partial T_{h}}{\partial z}=-\lambda_{a} \frac{\partial T_{a}}{\partial z} ; \frac{\partial C_{f}}{\partial z}=0 ; \frac{\partial \psi}{\partial z}=0 ; \\
z=z_{2}, 0<r<r_{1},-\lambda_{a} \frac{\partial T_{a}}{\partial z}-Q_{\mathrm{ef}} W_{\mathrm{ef}}-Q_{\mathrm{eo}} W_{\mathrm{eo}}=-\lambda_{f} \frac{\partial T_{f}}{\partial z} ; \rho_{12} D \frac{\partial C_{f}}{\partial z}=W_{e f} ; \\
\frac{W_{e f}}{\rho_{12}} ; \\
z=z_{\mathrm{L}}, 0<r<r_{\mathrm{L}} \frac{\partial^{2} T_{a}}{\partial z^{2}}=0 ; \frac{\partial^{2} C_{f}}{\partial z^{2}}=0 ; \frac{\partial \psi}{\partial z}=0 .
\end{gathered}
$$

The thermophysical properties of the gel fuel were calculated using the following equations [29]:

$$
\begin{aligned}
& \lambda_{f}=(1-\varphi) \lambda_{f}+\varphi \lambda_{a} ; \\
& C_{f}=(1-\varphi) C_{f}+\varphi C_{a} ; \\
& \rho_{f}=(1-\varphi) \rho_{f}+\varphi \rho_{a} .
\end{aligned}
$$


The mass evaporation rates for the fuel and the oxidizer were calculated using the following equations [29]:

$$
\begin{gathered}
W_{\mathrm{ef}}=\frac{\varphi A\left(P_{\mathrm{e}}^{\mathrm{n}}-P_{\mathrm{e}}\right)}{\sqrt{2 \pi R T_{\mathrm{h}} / M_{12}}} ; \\
W_{\mathrm{eo}}=\frac{(1-\varphi) A\left(P_{\mathrm{e}}^{\mathrm{n}}-P_{\mathrm{e}}\right)}{\sqrt{2 \pi R T_{\mathrm{h}} / M_{13}}} .
\end{gathered}
$$

The mass rate of fuel melting was calculated by the following formula:

$$
W_{\text {melt }}=V_{\text {melt }} \rho_{f}
$$

The system of nonlinear, nonstationary partial differential Equations (1)-(7) is solved by the finite difference method. To solve the system of one-dimensional difference equations, the sweep method was used. To improve the solution accuracy, at least 200 nodes of the difference grid were set for each of the coordinates. This dimension was chosen so that the area corresponding to the smallest object (fuel sample) was at least 10 nodes. The fuel sample corresponded to an area with no less than 20 nodes. This discretization was sufficient to solve the presented system of equations. For time discretization, a step of $10^{-3} \mathrm{~s}$ was used. This step corresponded to the accuracy of the experiment [33], the data of which were used in this work.

\subsection{Dominance of Radiant Heat Flux on the Surface of the Gel Fuel}

When formulating the problem statement, it was assumed that the gel fuel, cooled to a temperature of $203 \mathrm{~K}$, is introduced into still air heated to high temperatures (973-1273 K) with the help of a holder. When the gel fuel is heated (mainly by radiant heat input), its surface temperature reaches the melting point of the fuel. A thin layer of thickener forms on the surface of the melt with a flammable liquid at the bottom. Then, complete evaporation of the flammable liquid from the free surface takes place. A flammable vapor-gas mixture is formed around the fuel sample. When the concentrations of the mixture components and temperatures sufficient for ignition are reached, ignition occurs. Convective gas fluxes in this area have not been described. The ignition criteria applied in the formulation of the heat and mass transfer problem (Figure 2) were assumed similarly to those for the ignition under the dominance of conductive heat flux to the surface of the gel fuel sample. The solution domain for the problem of heat and mass transfer during radiant heating is shown in Figure 2.

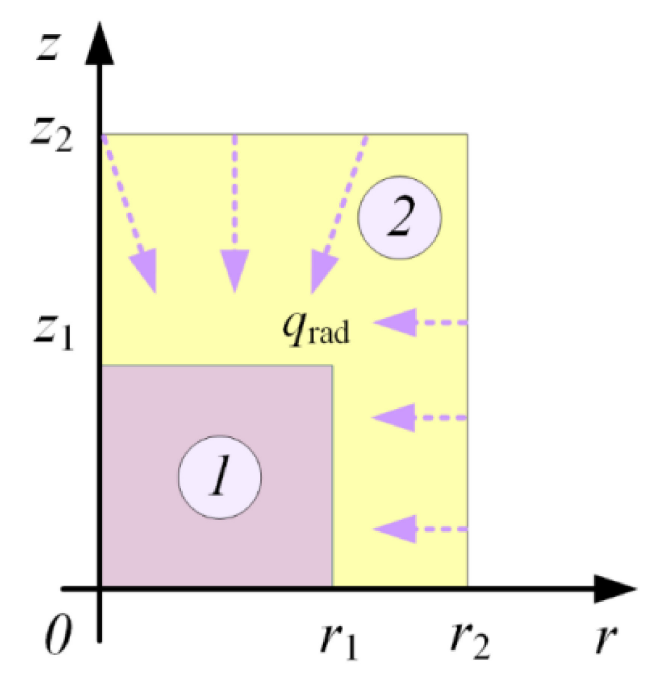

Figure 2. Scheme of the solution domain for the heat and mass transfer problem under radiant heating: 1-gel fuel sample; 2-air. 
The system of nonstationary partial differential equations is provided above. Initial conditions: $T=T_{f}$ at $0<r<r_{1}, 0<z<z_{1} ; T=T_{\mathrm{a}}, C_{f}=0, \psi=0, \omega=0$ at $0<r<r_{1}, z_{1}<z<z_{2}$, $r_{1}<r<r_{\mathrm{L}}, z_{1}<z<z_{2}$. Boundary conditions:

$$
\begin{aligned}
& r=0,0<z<z_{1}, \frac{\partial T_{f}}{\partial r}=0 \\
& r=r_{1}, 0<z<z_{1},-\lambda_{a} \frac{\partial T_{a}}{\partial r}-Q_{\mathrm{ef}} W_{\mathrm{ef}}-Q_{\mathrm{eo}} W_{\mathrm{eo}}=-\lambda_{f} \frac{\partial T_{f}}{\partial r} ; \rho_{12} D \frac{\partial C_{f}}{\partial r}=W_{e f} ; \\
& \frac{\partial \psi}{\partial r}=\frac{W_{e f}}{\rho_{12}} ; \\
& r=0, z_{1}<z<z_{\mathrm{L}}, \frac{\partial T_{a}}{\partial r}=0 ; \frac{\partial C_{f}}{\partial r}=0 ; \frac{\partial \psi}{\partial r}=0 ; r=r_{\mathrm{L}}, 0<z<z_{\mathrm{L}},-\lambda_{a} \frac{\partial T_{a}}{\partial r}=q_{\text {rad }} ; \\
& \frac{\partial^{2} C_{f}}{\partial r^{2}}=0 ; \frac{\partial \psi}{\partial r}=0 ; \\
& z=0,0<r<r_{1}, \frac{\partial T_{f}}{\partial z}=0 \\
& z=0, r_{1}<r<r_{\mathrm{L}}, \frac{\partial T_{a}}{\partial z}=0 ; \frac{\partial C_{f}}{\partial z}=0 ; \frac{\partial \psi}{\partial z}=0 ; \\
& z=z_{1}, 0<r<r_{1},-\lambda_{a} \frac{\partial T a}{\partial z}-Q_{\mathrm{ef}} W_{\mathrm{ef}}-Q_{\mathrm{eo}} W_{\mathrm{eo}}=-\lambda f \frac{\partial T f}{\partial z} ; \rho_{12} D \frac{\partial C_{f}}{\partial z}=W_{e f} ; \\
& \frac{\partial \psi}{\partial z}=\frac{W_{e f}}{\rho_{12}} \\
& z=z_{\mathrm{L}}, 0<r<r_{\mathrm{L}},-\lambda_{a} \frac{\partial T_{a}}{\partial z}=q_{\text {rad }} ; \frac{\partial^{2} C_{f}}{\partial z^{2}}=0 ; \frac{\partial \psi}{\partial z}=0 .
\end{aligned}
$$

The density of heat flux dissipated from the heating source through radiant heat transfer was calculated by the following equation [34]:

$$
q_{\mathrm{rad}}=\sigma \varepsilon T_{a}^{4}
$$

\subsection{Dominance of Convective Heat Flux on the Surface of the Gel Fuel}

When formulating the problem statement, it was assumed that the gel fuel sample with $T_{0}=203 \mathrm{~K}$ was ignited by a burner. The rise in the temperature of the sample occurred due to external air, whose temperature was higher than the fuel temperature. Ignition took place at the air velocity $U_{\mathrm{v}}$, adjusted in the range of $0.2-6 \mathrm{~m} / \mathrm{s}$. The solution domain for the problem of heat and mass transfer under convective heating is shown in Figure 3.

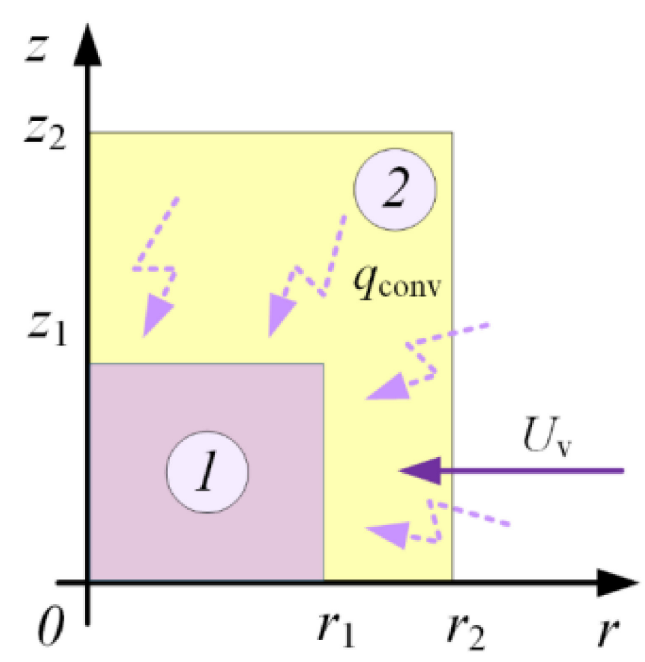

Figure 3. Scheme of the solution domain for the heat and mass transfer problem under convective heating: 1-gel fuel sample; 2-air. 
To explain a complex of related heat and mass transfer processes under convective heating at $0<\tau<\tau_{\mathrm{d}}$, a system of nonstationary partial differential Equations (1)-(7) was used. Initial conditions: $T=T_{\mathrm{f}}$ at $0<r<r_{1}, 0<z<z_{1} ; T=T_{\mathrm{a}}, C_{f}=0, \psi=0, \omega=0$ at $0<r<$ $r_{1}, \mathrm{z}_{1}<z<z_{2}, r_{1}<r<r_{\mathrm{L}}, \mathrm{z}_{1}<z<z_{2}$. Boundary conditions:

$$
\begin{aligned}
& r=0,0<z<z_{1}, \frac{\partial T_{f}}{\partial r}=0 ; \\
& \begin{array}{c}
r=r_{1}, 0<z<z_{1},-\lambda_{a} \frac{\partial T_{a}}{\partial r}-Q_{\mathrm{ef}} W_{\mathrm{ef}}-Q_{\mathrm{eoo}} W_{\mathrm{eo}}=-\lambda f \frac{\partial T_{f}}{\partial r} ; \rho_{12} D \frac{\partial C_{f}}{\partial r}=W_{e f} ; \\
\frac{\partial \psi}{\partial r}=\frac{W_{e f}}{\rho_{12}} ;
\end{array} \\
& r=0, r=r_{\mathrm{L}}, 0<z<z_{\mathrm{L}}-\lambda_{a} \frac{\partial T_{a}}{\partial r}=q_{\mathrm{conv}} ; \frac{\partial^{2} C_{f}}{\partial r^{2}}=0 ; \frac{\partial \psi}{\partial r}=U v ; \\
& z=0,0<r<r_{1}, \frac{\partial T_{f}}{\partial z}=0 ; \\
& z=0, r_{1}<r<r_{\mathrm{L}}, \frac{\partial T_{a}}{\partial z}=0 ; \frac{\partial^{2} C_{f}}{\partial z^{2}}=0 ; \frac{\partial \psi}{\partial z}=0 ; \\
& z=z_{1}, 0<r<r_{1},-\lambda_{a} \frac{\partial T_{a}}{\partial z}-Q_{\mathrm{ef}} W_{\mathrm{ef}}-Q_{\mathrm{eo}} W_{\mathrm{eo}}=-\lambda f \frac{\partial T_{f}}{\partial z} ; \rho_{12} D \frac{\partial C_{f}}{\partial z}=W_{e f} ; \\
& \frac{\partial \psi}{\partial z}=\frac{W_{e f}}{\rho_{12}} ; \\
& z=z_{\mathrm{L},} 0<r<r_{\mathrm{L},}-\lambda_{a} \frac{\partial T_{a}}{\partial z}=q_{\mathrm{conv}} ; \frac{\partial^{2} C_{f}}{\partial z^{2}}=0 ; \frac{\partial \psi}{\partial z}=U v .
\end{aligned}
$$

The density of the heat flux dissipated from the heating source through convective heat transfer was calculated by the following equation [34]:

$$
\begin{gathered}
q_{\text {conv }}=\alpha\left(T_{a}-T_{f}\right) . \\
\alpha=\frac{N u \cdot \lambda}{d} . \\
N u=2+0.74 \operatorname{Re}^{0.5} \cdot \operatorname{Pr}^{0.33} . \\
\operatorname{Re}=\frac{U_{v} \cdot d}{v} . \\
\operatorname{Pr}=\frac{v}{a} .
\end{gathered}
$$

\section{Results and Discussion}

The theoretical research findings include the ranges of the variation of the ignition delay time values for gel fuel for three heating schemes: radiant, conductive and convective. Figure 4 shows the theoretical dependencies established between the ignition delay time of the gel fuel and the temperature of the heated air (973-1273 K) under the conditions of convective, conductive and radiant heating. It can be seen that the maximum ignition delay times correspond to the radiant heating scheme (4.6-2.3 s, when the temperature was being increased from $973 \mathrm{~K}$ to $1273 \mathrm{~K}$ ). Under conductive heating, the $\tau$ decrease from $3.7 \mathrm{~s}$ to $1.5 \mathrm{~s}$, depending on the temperature of the source represented by the substrate. The minimum ignition delay times correspond to convective heating and are in the range of 2.1-0.3 s. For radiant and conductive heating, when $T$ varies between $973 \mathrm{~K}$ and $1273 \mathrm{~K}$, the ignition delay time values differ by approximately the factor of 2; for convective heating, the difference is 7 times. These peculiarities can be explained by the fact that during conductive and radiant heating, the flux of heat to the fuel surface changes rather moderately as the temperature increases, as compared to convective heat transfer. Additionally, under conductive heating, the heat is supplied to the fuel surface from one side only, while for convective and radiant 
heating, the fuel sample is heated from all sides. Therefore, deep layers of the fuel sample are warmed up faster.

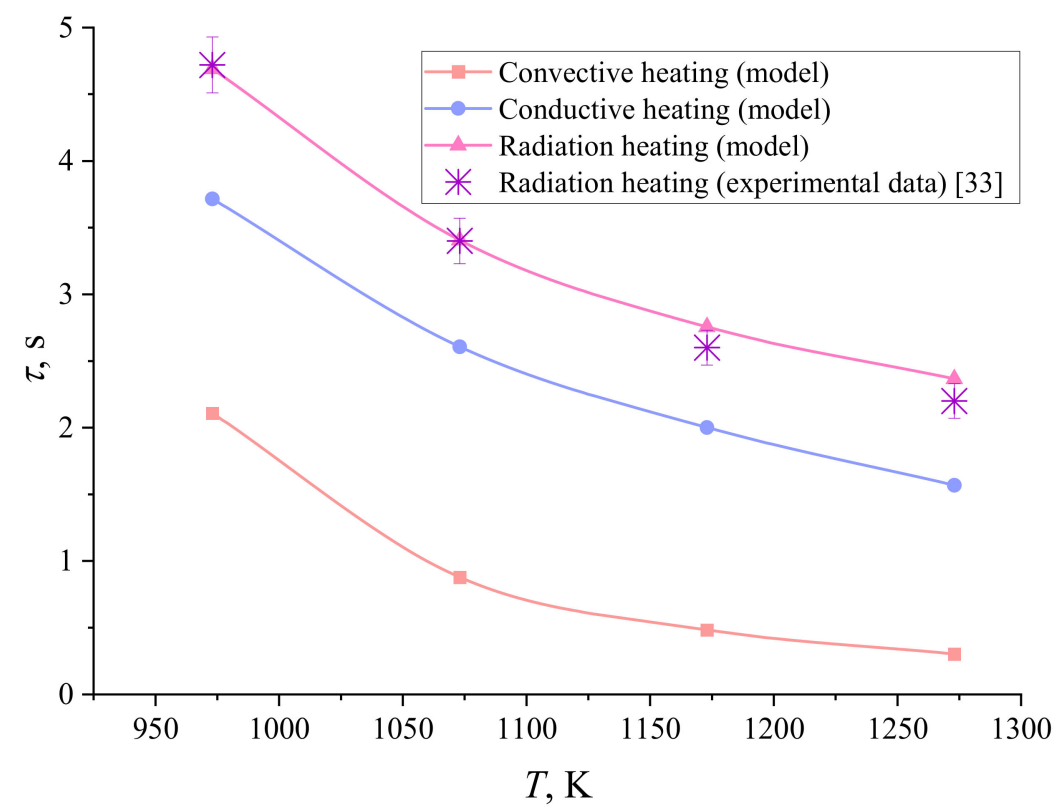

Figure 4. Theoretical and experimental dependencies $\tau$ of the gel fuel on $T$ in the conditions of convective, conductive and radiant heating (data from [33]).

As a result of the numerical modeling of the process being researched, the ignition delay times of the gel fuel were obtained. These values are in satisfactory agreement with the corresponding experimental data in [33] (Figure 4) where the temperature $T$ varies between 973 and $1273 \mathrm{~K}$, and the initial fuel temperature equals $203 \mathrm{~K}$. The difference between the theoretical and experimental values of ignition delay times does not exceed the measurement error $\tau$ in the experiments in [33]. Based on the satisfactory agreement between the results of the mathematical simulation and the experimental data in [33], it can be concluded that the developed mathematical model adequately describes a group of interdependent physicochemical processes taking place during the ignition of gel fuel in a high-temperature environment.

The convective heat exchange scheme is more efficient in terms of $\tau$. This is also due to the fact that the vapors of the combustible component having a high temperature are carried away from the surface of the fuel sample and then mixed with the oxidizer. This forms a steam-gas mixture with conditions under which oxidation reactions proceed rather intensively. By varying the temperature and the airflow rate, it is possible to control the position of the ignition zone relative to the surface of the fuel sample. In particular, at relatively low temperatures and airflow rates, the ignition zone was located behind the fuel sample. This was due to the fact that relatively cold vapors did not have time to warm up to a temperature at which oxidation reactions are accelerated. Only after traveling a certain distance from the fuel sample, the vapors heated up, and their reactions were intensified.

With a rise in the air temperature and rate, the position of the ignition zone shifted in the direction of the fuel sample (Figures 5-7). 


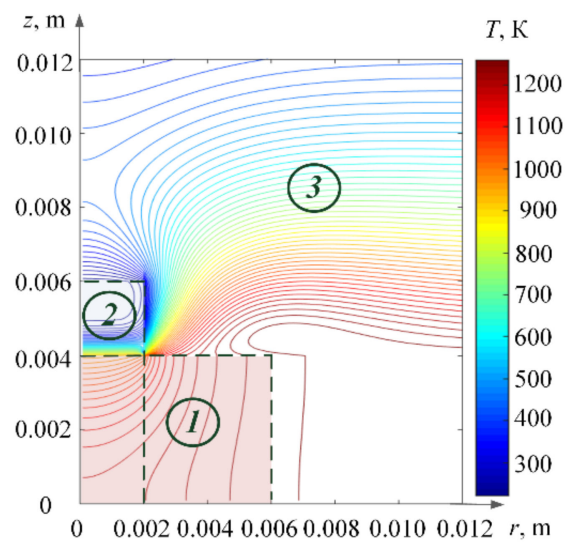

(a)

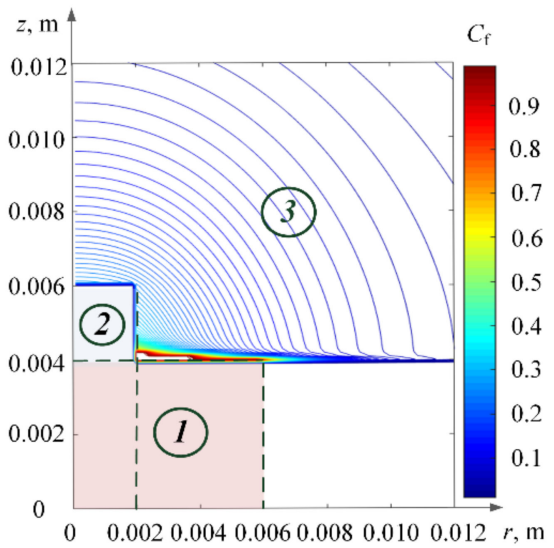

(b)

Figure 5. (a) Temperature field under conductive heating; (b) Field of relative concentrations of fuel vapors under conductive heating; 1-heated surface, 2-gel fuel sample, 3-steam-gas mixture. Heating source temperature: $T=1273 \mathrm{~K}$.

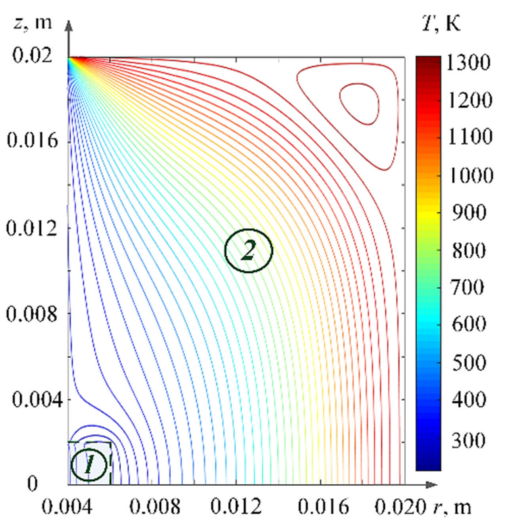

(a)

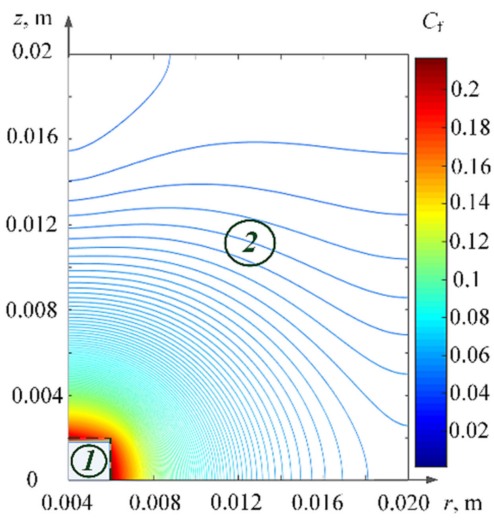

(b)

Figure 6. (a) Temperature field under radiant heating; (b) Field of relative concentrations of fuel vapors under radiant heating; 1 -gel fuel sample, 2 -steam-gas mixture. Conditions: $T=1273 \mathrm{~K}$, $\varepsilon=0.85$.

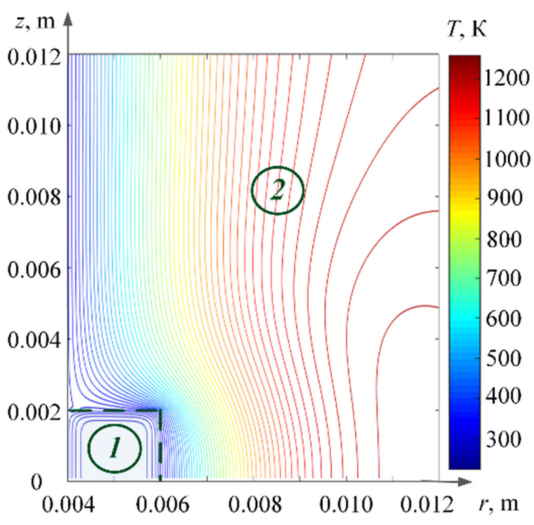

(a)

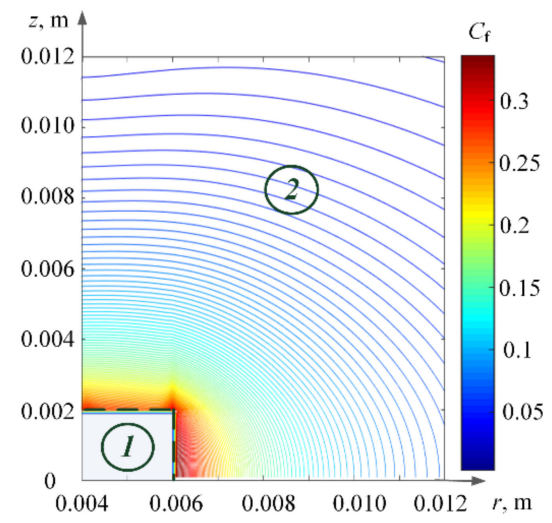

(b)

Figure 7. (a) Temperature field under convective heating; (b) Field of relative concentrations of fuel vapors under convective heating; 1 -gel fuel sample, 2-steam-gas mixture. Conditions: $T=1273 \mathrm{~K}$, $\alpha=50 \mathrm{~W} /\left(\mathrm{m}^{2} \cdot \mathrm{K}\right)$. 
Table 2 shows the ignition delay time values determined when the radiant heat flux was dominant and the emissivity (i.e., the degree of darkness) was varied. Under radiant heating, the minimum temperature $T=873 \mathrm{~K}$ is required. When the temperature $T$ is varied in the range of $873-1273 \mathrm{~K}$ and the emissivity is varied in the range of $0.85-0.99$, the ignition delay times of the gel fuel vary between $8.776 \mathrm{~s}$ and $2.366 \mathrm{~s}$ (Table 2).

Table 2. Ignition delay times under radiant heating when the emissivity value is varied.

\begin{tabular}{ccccc}
\hline $\boldsymbol{T}, \mathbf{K}$ & $\boldsymbol{\tau}, \mathbf{s}$ at $\boldsymbol{\varepsilon}=\mathbf{0 . 8 5}$ & $\boldsymbol{\tau}, \mathbf{s}$ at $\varepsilon=\mathbf{0 . 9 0}$ & $\boldsymbol{\tau}, \mathbf{s}$ at $\varepsilon=\mathbf{0 . 9 5}$ & $\boldsymbol{\tau}, \mathbf{s}$ at $\varepsilon=\mathbf{0 . 9 9}$ \\
\hline 873 & 8.776 & 8.776 & 8.766 & 8.763 \\
973 & 4.691 & 4.690 & 4.688 & 4.688 \\
1073 & 3.407 & 3.406 & 3.405 & 3.405 \\
1173 & 2.757 & 2.756 & 2.756 & 2.756 \\
1273 & 2.366 & 2.366 & 2.366 & 2.366 \\
\hline
\end{tabular}

Emissivity does not affect the ignition delay times, and this is especially noticeable at high temperatures (above $1073 \mathrm{~K}$ ).

At temperatures below $1073 \mathrm{~K}$, the effect of the emissivity factor is very weakly expressed. At $\varepsilon=0.85-0.99$ and $T=873 \mathrm{~K}, \tau$ decreases from $8.776 \mathrm{~s}$ to $8.763 \mathrm{~s}$ (i.e., the change is less than $1 \%$ ).

It was found that under the conditions of convective heating, there is a significant decrease in the ignition delay time of the gel fuel (up to $66 \%$ on average). Here, the heat transfer coefficient changes in the range of $0-200 \mathrm{~W} /\left(\mathrm{m}^{2} \cdot \mathrm{K}\right)$, which corresponds to the air flow velocity of up to $6 \mathrm{~m} / \mathrm{s}$ (Figure 8). The minimum decrease in the ignition delay time, i.e., from $0.778 \mathrm{~s}$ to $0.319 \mathrm{~s}$ (by $59 \%$ ), corresponds to a heating temperature of $1073 \mathrm{~K}$. The maximum decrease is at a temperature of $1273 \mathrm{~K}$, whereby $\tau$ changes from $0.302 \mathrm{~s}$ to 0.088 $\mathrm{s}$ (by $71 \%$ ). For both cases, the value of $\alpha$ varies between 0 and $200 \mathrm{~W} /\left(\mathrm{m}^{2} \cdot \mathrm{K}\right)$ (Figure 8 ).

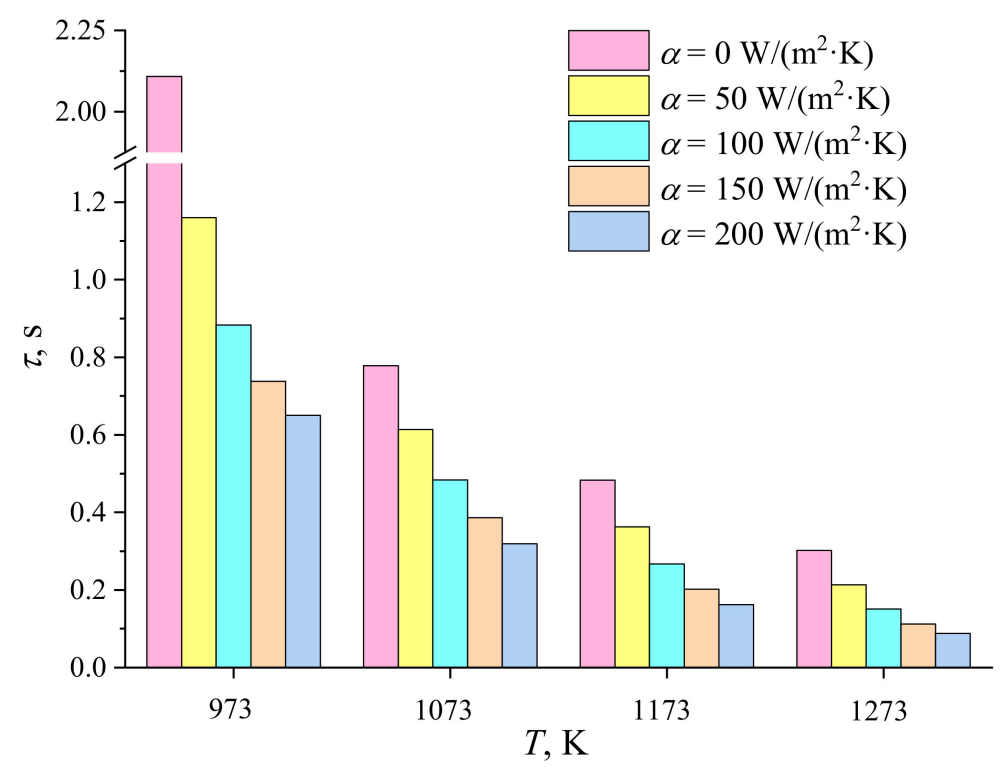

Figure 8. Theoretical dependency $\tau$ on $T$ when varying the heat transfer coefficient $\alpha$ under convective heating conditions.

The minimum temperature required to initiate the ignition of the gel fuel under convective heating conditions is $973 \mathrm{~K}$. It is important to note that in real-life engines and combustion chambers of power plants, there is a possibility of adjusting the oxidizer flow rate when it is mixed with fuel in a wide range. According to calculations, in a number of cases, it is more efficient to increase the rate of the fuel and oxidizer flow movement as compared to the adjustment of the temperature in the reaction zone. 
It was found that the delay times of the ignition of the gel fuel under the conditions of conductive heating increase nonlinearly with an increase in the activation energy of the fuel vapors' oxidation reaction (Figure 9).

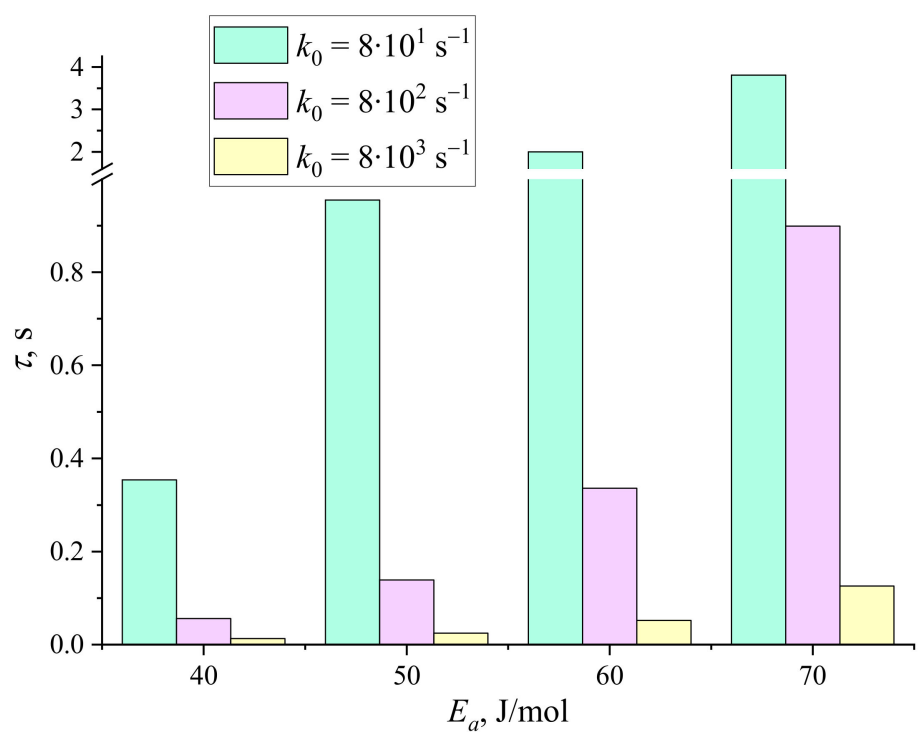

Figure 9. Theoretical dependency of the ignition delay time $\tau$ on $E_{a}$ when $k_{0}$ is varied under the conditions of conductive heating $(T=1173 \mathrm{~K})$.

This can be explained by the fact that an increase in the activation energy causes the combustion rate to decrease significantly. This leads to a decrease in the mass of injected vapors of the combustible gel fuel and to a decrease in the rate of combustion taking place with an oxidizer.

Consequently, the rate of heating of the fuel particle will decline, and the delay time will rise, which is well illustrated in Figure 9. A rise in the activation energy physically translates into a larger energy barrier that must be overcome to intensify the chemical reaction. When the activation energy is increased, the flow of reaction and evaporation processes that are in a nonlinear dependency from the temperature leads to a nonlinear increase in the ignition delay time of the gel fuel (Figure 9).

The minimum temperature required to initiate the ignition of the gel fuel under convective heating conditions is $873 \mathrm{~K}$. Under the conditions of conductive heating, an increase in the pre-exponential factor of the oxidation reaction from $8 \times 10^{1} \mathrm{~s}^{-1}$ to $8 \times 10^{3} \mathrm{~s}^{-1}$ at a constant activation energy will lead to an appreciably lower in the ignition delay times (up to $96 \%$ on average) at $T=1173 \mathrm{~K}$. If the pre-exponential factor is constant, then increasing the activation energy from 40 to $70 \mathrm{~J} / \mathrm{mol}$ will cause the ignition delay time to increase to $90 \%$.

Under the conditions of conductive heating, the maximum ignition delay time of the gel fuel is realized at $E_{\mathrm{a}}=70 \mathrm{~J} / \mathrm{mol}$ and $k_{0}=8 \times 10^{1} \mathrm{~s}^{-1}$, and it equals $3.8 \mathrm{~s}$. The minimum ignition delay time $(\tau=0.013 \mathrm{~s})$ corresponds to $E_{\mathrm{a}}=40 \mathrm{~J} / \mathrm{mol}$ and $k_{0}=8 \times 10^{3} \mathrm{~s}^{-1}$. The ranges of changes in the fuel ignition delay times determined while varying $E_{a}$ and $k_{0}$ are of interest when using identical ignition systems under the operating conditions of engines and combustion chambers with fuels of different component compositions.

It was found that the critical flow of heat densities at which stable ignition of the gel fuel with an initial temperature of $203 \mathrm{~K}$ occurs (Figure 10) are as follows: $110 \mathrm{~kW} / \mathrm{m}^{2}$ for the radiant heating scheme, $149 \mathrm{~kW} / \mathrm{m}^{2}$ for the convective heating scheme and $123 \mathrm{~kW} / \mathrm{m}^{2}$ for the conductive heating scheme. The corresponding differences for the three heating schemes are due to the difference in the heated surface areas of the gel fuel samples. The greater this area, the more intensive heating is, and it increases not only for near-surface layers, but also especially for deep layers. In addition, the greater the mass concentration 
of the injected fuel vapors, the more intense their interaction with the oxidizer, hence the ignition process is accelerated. The difference between the heat flux densities obtained under the convective-radiant heating conditions and the values for gel fuel combustion presented in [35] is due to the initial temperatures of the fuel samples. In [35], at the initial temperature of the gel fuel at $293 \mathrm{~K}$, the heat flux density varied in the range of $40-100 \mathrm{~kW} / \mathrm{m}^{2}$ while the heat transfer coefficient varied in the range from 33 to $77 \mathrm{~W} / \mathrm{m}^{2} \cdot \mathrm{K}$ and the heating temperature was in a similar range of $973-1273 \mathrm{~K}$. The calculated heat flux stays within the range of $30-300 \mathrm{~kW} / \mathrm{m}^{2}$ obtained in [36] by the ignition of a composite fuel based on ammonium perchlorate and butyl rubber during conductive heating with a metal particle. The difference in the minimum threshold of the heat flux found in [36] can be explained by significant differences in the conditions of fuel heating by different sources and significant differences in the thermophysical and kinetic characteristics of the condensed substances in [36] and the gel fuels.

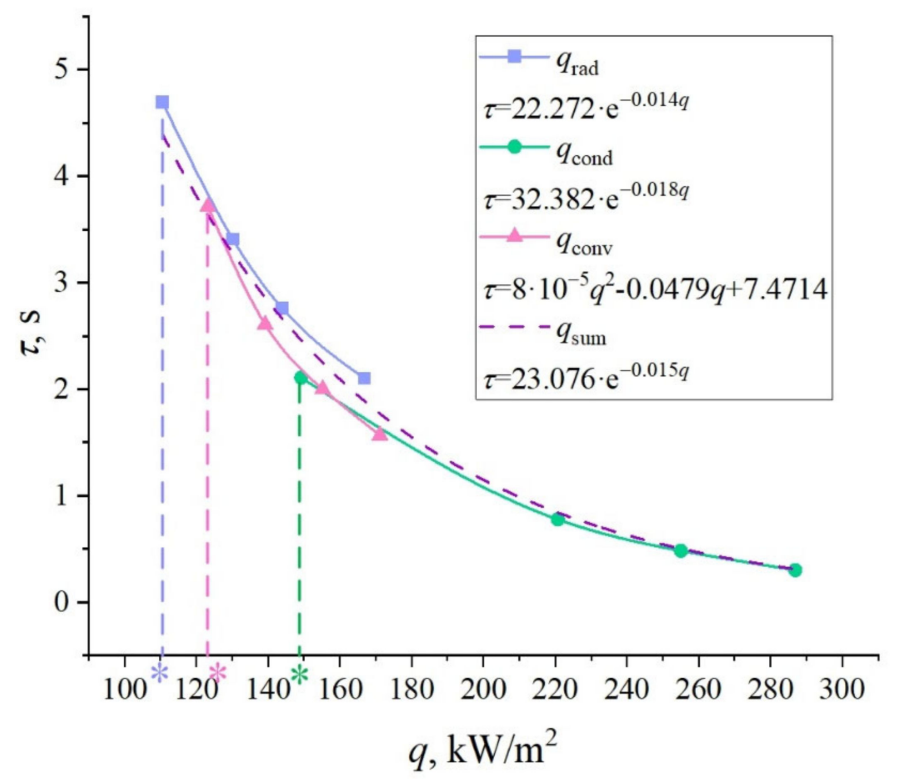

Figure 10. Heat flux densities during radiant, convective and conductive ignition of the gel fuel $\left(T_{f}=203 \mathrm{~K}\right)$ at heating temperatures in the range of 973-1273 K; approximation expressions for the ignition delay times ${ }^{*}$ is the critical heat flux density at which the gel fuel is ignited through different heating schemes).

Within the framework of this study, approximation expressions for the dependencies of the ignition delay times of a gel fuel on the heat flux density were obtained (Figure 10). The expressions can be used to determine the relation between the primary and secondary initial parameters and the characteristics of the combustion initiation process for a gel fuel. The model developed in this research work can be used not only for detecting $\tau$ of promising gel fuels with different component compositions, but also for analyzing the reaction conditions of other condensed substances that are stored at cryogenic temperatures in their initial form.

\section{Conclusions}

A mathematical model was developed for the numerical analysis of the ignition for a gel fuel under heating conditions with the dominance of conductive, convective and radiant heat fluxes. The developed model made it possible to establish the dependency of the key process characteristic (i.e., the ignition delay time) on the following factors: (i) temperature, under the conditions of a varying emissivity and energy heat transfer coefficient; (ii) activation energy of the fuel vapor oxidation reaction, under the conditions of a varying pre-exponential factor of the fuel vapor oxidation reaction. Radiant heating 
corresponds to the maximum ignition delay times of the gel fuel observed in the range of 2.3-4.7 s. For conductive heating, the ignition delay times are 1.5-3.7 s at the heating temperature of $973-1273 \mathrm{~K}$. The minimum ignition delay times correspond to the conditions of convective heating, and they vary between $0.302 \mathrm{~s}$ and $2.108 \mathrm{~s}$ at similar temperatures.

It was shown that the critical heat flux densities at which the ignition of the gel fuel with the initial temperature of $203 \mathrm{~K}$ occurred were as follows: $110 \mathrm{~kW} / \mathrm{m}^{2}$ for radiant heating, $149 \mathrm{~kW} / \mathrm{m}^{2}$ for convective heating and $123 \mathrm{~kW} / \mathrm{m}^{2}$ for conductive heating.

These values illustrate the critical thermal conditions necessary and sufficient to initiate the combustion of promising gel fuels in power plants' combustion chambers and engines.

Author Contributions: P.S. developed the ignition model and wrote the paper; O.G. performed the modeling and processed the results. All authors have read and agreed to the published version of the manuscript.

Funding: This research was funded by a grant from the Ministry of Science and Higher Education of Russia, Agreement No.: 075-15-2020-806 (Contract No.: 13.1902.21.0014).

Institutional Review Board Statement: Not applicable.

Informed Consent Statement: Not applicable.

Data Availability Statement: Not applicable.

Conflicts of Interest: The authors have no conflicts of interest to declare.

\section{Nomenclature}

Greek letters

$\begin{array}{ll}\alpha & \text { Convection heat transfer coefficient, } \mathrm{W} /\left(\mathrm{m}^{2} \cdot \mathrm{K}\right) \\ \Psi & \text { Stream function, } \mathrm{m}^{2} / \mathrm{s} \\ \omega & \text { Vorticity vector, } \mathrm{s}^{-1} \\ \beta & \text { Coefficient of thermal expansion, } \mathrm{K}^{-1} \\ \varepsilon & \text { Emissivity coefficient } \\ \varphi & \text { Dimensionless combustible part of fuel } \\ \lambda & \text { Thermal conductivity, } \mathrm{W} /(\mathrm{m} \cdot \mathrm{K}) \\ v & \text { Kinetic viscosity, } \mathrm{m}^{2} / \mathrm{s} \\ \tau & \text { Ignition delay time, } \mathrm{s} \\ \rho & \text { Density, kg/m } \mathrm{m}^{3} \\ \sigma & \text { Stefan-Boltzmann constant, } \mathrm{W} /\left(\mathrm{m}^{2} \cdot \mathrm{K}^{4}\right) \\ \mathrm{Latin} \text { letters } & \\ A & \text { Accommodation coefficient } \\ a & \text { Temperature conductivity coefficient, } \mathrm{m}^{2} / \mathrm{s} \\ C & \text { Specific heat, } \mathrm{J} /(\mathrm{kg} \cdot \mathrm{K}) \\ C_{\mathrm{o}} & \text { Dimensionless concentration of oxidant vapors } \\ C_{f} & \text { Dimensionless concentration of fuel vapors } \\ C_{\mathrm{g}} & \text { Dimensionless inert gas concentration } \\ D & \text { Diffusion coefficient, } \mathrm{m}^{2} / \mathrm{s} \\ d & \text { Diameter of fuel particle, } \mathrm{m} \\ E_{\mathrm{a}} & \text { Activation energy of oxidizing reaction, } \mathrm{J} / \mathrm{mole} \\ g & \text { Gravity acceleration, } \mathrm{m} / \mathrm{s}^{2} \\ k_{0} & \text { Oxidizing reaction pre-exponential factor, } \mathrm{s}^{-1} \\ M & \text { Evaporating component molecular mass, } \mathrm{kg} / \mathrm{kmole} \\ N u & \text { Nusselt number } \\ P_{\mathrm{e}} & \text { Vapor pressure over the fuel surface, } \mathrm{N} / \mathrm{m}^{2} \\ P_{\mathrm{e}} \mathrm{n} & \text { Equilibrium vapor pressure, Pa } \\ & \end{array}$




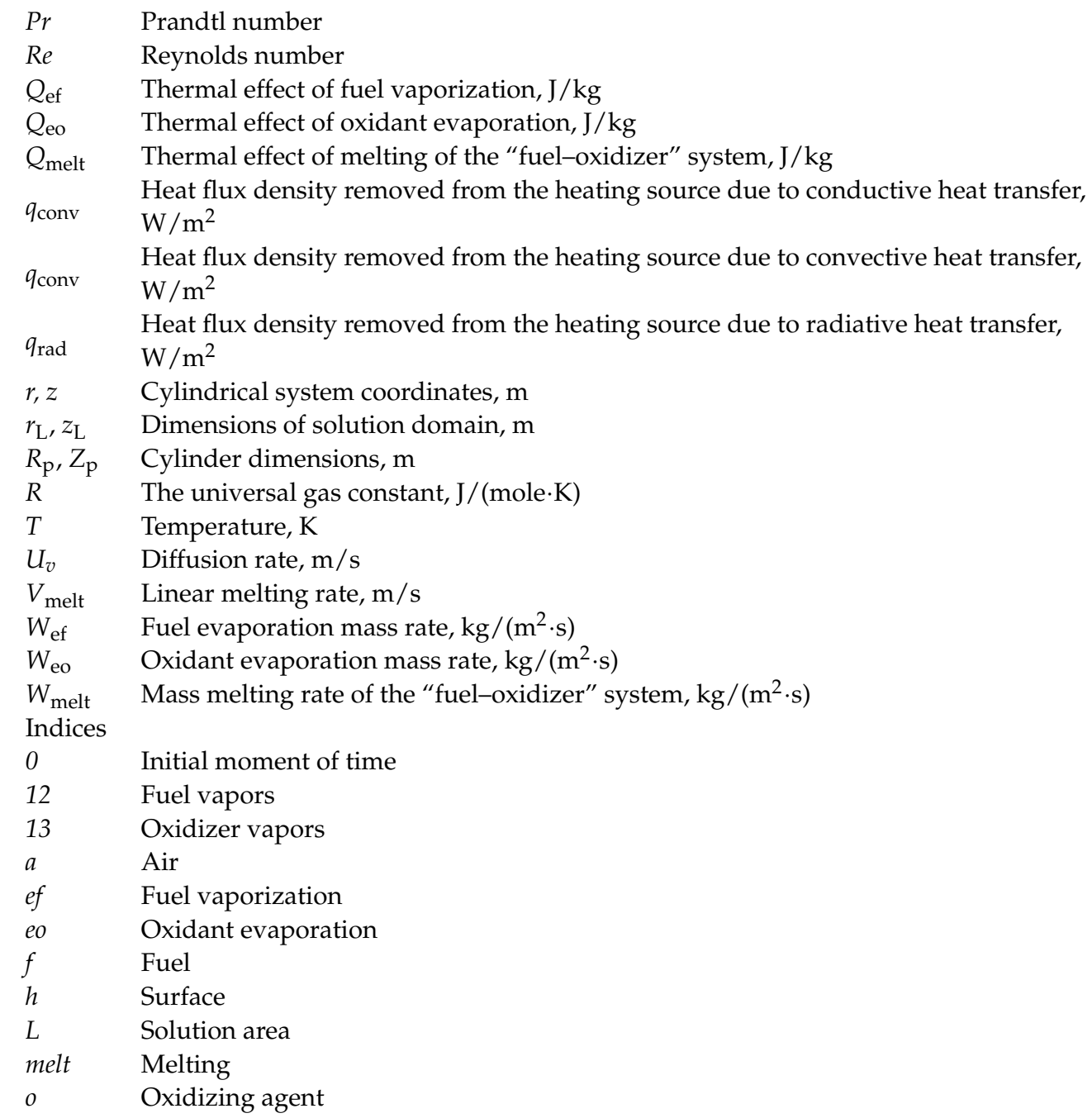

\section{References}

1. Vujanović, M.; Wang, Q.; Mohsen, M.; Duić, N.; Yan, J. Recent progress in sustainable energy-efficient technologies and environmental impacts on energy systems. Appl. Energy 2021, 283, 116280. [CrossRef]

2. Xiao, Y.; Xia, Z.; Huang, L.; Ma, L.; Yang, D. Experimental investigation of the effects of chamber length and boron content on boron-based gel fuel ramjet performance. Acta Astronaut. 2019, 160, 101-105. [CrossRef]

3. Ciezki, H.K.; Naumann, K.W. Some Aspects on Safety and Environmental Impact of the German Green Gel Propulsion Technology. Propellants Explos. Pyrotech. 2016, 41, 539-547. [CrossRef]

4. Natan, B.; Rahimi, S. The status of gel propellants in year 2000. Int. J. Energy Mater. Chem. Propuls. 2002, 5, 172-194. [CrossRef]

5. Cao, Q.L.; Wu, W.T.; Liao, W.H.; Feng, F.; Massoudi, M. Effects of temperature on the flow and heat transfer in gel fuels: A numerical study. Energies 2020, 13, 821. [CrossRef]

6. Rahimi, S.; Peretz, A.; Natan, B. Rheological Matching of Gel Propellants. J. Propuls. Power 2012, 26, 376-378. [CrossRef]

7. Vershinina, K.Y.; Glushkov, D.O.; Nigay, A.G.; Yanovsky, V.A.; Yashutina, O.S. Oil-Filled Cryogels: New Approach for Storage and Utilization of Liquid Combustible Wastes. Ind. Eng. Chem. Res. 2019, 58, 6830-6840. [CrossRef]

8. Verma, M.; Gupta, B.L.; Pandey, M. Formulation \& Storage Studies on Hydrazine-Based Gelled Propellants. Def. Sci. J. 1996, 46, 435-442. [CrossRef]

9. Sun, D.; Cai, W.; Li, C.; Lu, J. Experimental study on atomization characteristics of high-energy-density fuels using a fuel slinger. Energy 2021, 234, 121222. [CrossRef]

10. Won, J.; Baek, S.W.; Kim, H.; Lee, H. The Viscosity and Combustion Characteristics of Single-Droplet Water-Diesel Emulsion. Energies 2019, 12, 1963. [CrossRef]

11. Glushkov, D.; Paushkina, K.; Shabardin, D.; Strizhak, P. Environmental aspects of converting municipal solid waste into energy as part of composite fuels. J. Clean. Prod. 2018, 201, 1029-1042. [CrossRef]

12. Caton, J.A. The thermodynamic characteristics of high efficiency, internal-combustion engines. Energy Convers. Manag. 2012, 58, 84-93. [CrossRef]

13. Liu, Z.; Hu, X.; He, Z.; Wu, J. Experimental Study on the Combustion and Microexplosion of Freely Falling Gelled Unsymmetrical Dimethylhydrazine (UDMH) Fuel Droplets. Energies 2012, 5, 3126-3136. [CrossRef] 
14. Nachmoni, G.; Natan, B. Combustion characteristics of gel fuels. Combust. Sci. Technol. 2000, 156, 139-157. [CrossRef]

15. Mishra, D.P.; Patyal, A.; Padhwal, M. Effects of gellant concentration on the burning and flame structure of organic gel propellant droplets. Fuel 2011, 90, 1805-1810. [CrossRef]

16. Padwal, M.B.; Mishra, D.P. Experimental Characterization of Gelled Jet A1 Spray Flames. Flow Turbul. Combust. 2016, 97, 295-337. [CrossRef]

17. Jyoti, B.V.S.; Naseem, M.S.; Baek, S.W. Hypergolicity and ignition delay study of pure and energized ethanol gel fuel with hydrogen peroxide. Combust. Flame 2017, 176, 318-325. [CrossRef]

18. Glushkov, D.O.; Nigay, A.G.; Yashutina, O.S. The gel fuel ignition at local conductive heating. Int. J. Heat Mass Transf. 2018, 127, 1203-1214. [CrossRef]

19. Solomon, Y.; Natan, B.; Cohen, Y. Combustion of gel fuels based on organic gellants. Combust. Flame 2009, 156, 261-268. [CrossRef]

20. He, B.; Nie, W.; He, H. Unsteady Combustion Model of Nonmetalized Organic Gel Fuel Droplet. Energy Fuels 2012, 26, 6627-6639. [CrossRef]

21. Kunin, A.; Greenberg, J.B.; Natan, B. A simple phenomenological model of an organic gel spray diffusion flame. Combust. Sci. Technol. 2008, 180, 27-44. [CrossRef]

22. Kunin, A.; Natan, B.; Greenberg, J.B. Theoretical Model of the Transient Combustion of Organic-Gellant-Based Gel Fuel Droplets. J. Propuls. Power 2012, 26, 765-771. [CrossRef]

23. Glushkov, D.O.; Kuznetsov, G.V.; Strizhak, P.A.; Taburchinov, R.I. Numerical simulation of gel fuel gas-phase ignition by a local source of limited heat content. Acta Astronaut. 2019, 163, 44-53. [CrossRef]

24. Glushkov, D.O.; Kosintsev, A.G.; Kuznetsov, G.V.; Vysokomorny, V.S. Numerical simulation of ignition of a typical gel fuel particle, based on organic polymer thickener, in a high-temperature air medium. Acta Astronaut. 2021, 178, 272-284. [CrossRef]

25. Liu, N.; Ma, B.; Liu, F.; Huang, W.; Xu, B.; Qu, L.; Yang, Y. Progress in research on composite cryogenic propellant tank for large aerospace vehicles. Compos. Part A Appl. Sci. Manuf. 2021, 143, 106297. [CrossRef]

26. Yilmaz, N. Performance and emission characteristics of a diesel engine fuelled with biodiesel-ethanol and biodiesel-methanol blends at elevated air temperatures. Fuel 2012, 94, 440-443. [CrossRef]

27. Li, N.; Mao, G.; Liu, Y. Effect of the Evaluation and Mechanism Analysis of a Novel Nanohybrid Pour Point Depressant on Facilitating Flow Properties of Crude Oil. Energy Fuels 2018, 32, 10563-10570. [CrossRef]

28. Kuznetsov, G.V.; Strizhak, P.A. Computational Investigation of Heat and Mass Transfer Processes in a Gel-Like Fuel Ignited by a Limited-Capacity Source. J. Eng. Phys. Thermophys. 2013, 86, 695-704. [CrossRef]

29. Gaydukova, O.S.; Misyura, S.Y.; Strizhak, P.A. Investigating regularities of gas hydrate ignition on a heated surface: Experiments and modelling. Combust. Flame 2021, 228, 78-88. [CrossRef]

30. Glushkov, D.O.; Kuznetsov, G.V.; Nigay, A.G.; Yashutina, O.S. Heat and mass transfer induced by the ignition of single gel propellant droplets. J. Energy Inst. 2019, 92, 1944-1955. [CrossRef]

31. Yang, Z.; Adeosun, A.; Kumfer, B.M.; Axelbaum, R.L. An approach to estimating flame radiation in combustion chambers containing suspended-particles. Fuel 2017, 199, 420-429. [CrossRef]

32. Paskonov, V.M.; Polezhaev, V.I.; Chudov, L.A. Numerical Modeling of Heat and Mass Transfer Processes; Nauka: Moscow, Russia, 1984.

33. Glushkov, D.O.; Nigay, A.G.; Yanovsky, V.A.; Yashutina, O.S. Effects of the Initial Gel Fuel Temperature on the Ignition Mechanism and Characteristics of Oil-Filled Cryogel Droplets in the High-Temperature Oxidizer Medium. Energy Fuels 2019, 33, 11812-11820. [CrossRef]

34. Kutateladze, S.S.; Leont'ev, A.I. Heat Transfer, Mass Transfer, and Friction in Turbulent Boundary Layers; Hemisphere: New York, NY, USA, 1989.

35. Glushkov, D.O.; Pleshko, A.O.; Yashutina, O.S. Influence of heating intensity and size of gel fuel droplets on ignition characteristics. Int. J. Heat Mass Transf. 2020, 156, 119895. [CrossRef]

36. Glushkov, D.O.; Kuznetsov, G.V.; Strizhak, P.A. Stability of composite solid propellant ignition by a local source of limited energy capacity. Combust. Explos. Shock Waves 2014, 50, 670-675. [CrossRef] 